\title{
A educação a distância na pós-graduação stricto sensu brasileira: limites e possibilidades
}

\author{
Vanessa Itacaramby Pardim $^{1}$, Emerson Antonio Maccari $^{2}$ \\ ${ }^{1}$ Departamento de Educação a Distância - Universidade Nove de Julho (UNINOVE) \\ Rua Vergueiro, 235/249 - Liberdade. CEP - 01.504-001 - São Paulo - SP - Brasil \\ ${ }^{2}$ Programa de Pós-Graduação Stricto Sensu - Universidade Nove de Julho (UNINOVE), \\ São Paulo - SP - Brasil. \\ itacaramby@uninove.br, maccari@uninove.br
}

\begin{abstract}
This paper had for objective to understand at what stage is the regulations about the use of Distance Education (DE) in the post graduation programs Brazilian. For this purpose, a qualitative research was chosen, of exploratory nature and data collecting a document research was the option. As a result it was found that the use of the DE in this level of teaching has been put into practice without specific orientation to the course coordinators, and the existent initiatives are a reaction to announcements issued by the Coordenação de Aperfeiçoamento de Pessoal de Nivel Superior, being circumscribed to six professional master's degrees offered in network by public institutions owned by Universidade Aberta do Brasil.
\end{abstract}

Resumo. Este trabalho teve por objetivo compreender em que estágio se encontra a regulamentação sobre o emprego da Educação a Distância (EaD) na pós-graduação stricto sensu brasileira. Para isso optou-se por uma pesquisa qualitativa, de natureza exploratória e para a coleta de dados utilizou-se a pesquisa documental. Como resultado verificou-se que o emprego da EaD neste nível de ensino vem sendo feito sem que haja orientações específicas aos coordenadores de curso e as iniciativas existentes são uma resposta a editais lançados pela Coordenação de Aperfeiçoamento de Pessoal de Nível Superior, estando circunscritas a seis mestrados profissionais ofertados em rede por instituições públicas pertencentes à Universidade Aberta do Brasil.

\section{Introdução}

Um dos temas em pauta nas discussões sobre os rumos da educação no Brasil é a educação a distância $(\mathrm{EaD})$, em grande monta por sua capacidade de ampliar o acesso à educação formal no país. Mas essa discussão é permeada, entre outros, pela questão da qualidade dos cursos que são oferecidos (Litto, 2012), o que dificulta a consolidação desta modalidade em todos os níveis de ensino, principalmente na pós-graduação stricto sensu.

A discussão sobre o uso da $\mathrm{EaD}$ em cursos de mestrado, acadêmicos e profissionais, e doutorado vem se intensificando, principalmente após a instalação de mestrados profissionais em rede, oferecidos no formato semipresencial, destinados, principalmente, à formação de professores que atuam nas redes públicas de ensino. Esses cursos são oferecidos por instituições de ensino superior (IES) públicas e pertencentes à Universidade Aberta do Brasil (UAB) que foi criada pelo Decreto $\mathrm{n}$. 
5.800 (2006) com a finalidade de expandir e interiorizar a oferta de cursos e programas de educação superior no Brasil, por meio do emprego da EaD.

A criação de mestrados profissionais em rede vai ao encontro do que prevê o Projeto de Lei n. 8035 (2010) que aprova o Plano Nacional de Educação (PNE) para o período de 2011-2020. O documento aprovado pela Câmara dos Deputados prevê 20 metas e, para que possam ser alcançadas, várias estratégias são delineadas. Dentre as metas estabelecidas, a de número 13 prevê "elevar a qualidade da educação superior pela ampliação da proporção de mestres e doutores do corpo docente em efetivo exercício no conjunto do sistema de educação superior para $75 \%$ (setenta e cinco por cento), sendo, do total, no mínimo, 35\% (trinta e cinco por cento) doutores" (Lei n. 8035,2010, p. 42).

Ainda neste sentido, há a meta 14 que prevê "elevar gradualmente o número de matrículas na pós-graduação stricto sensu, de modo a atingir a titulação anual de 60.000 (sessenta mil) mestres e 25.000 (vinte e cinco mil) doutores" (idem, p. 44). A viabilização da meta 14 está condicionada a várias estratégias, entre elas temos a 14.4 que prevê a expansão da "oferta de cursos de pós-graduação stricto sensu, utilizando inclusive metodologias, recursos e tecnologias de educação a distância (ibidem, p. 44).

É válido ressaltar que a estratégia supramencionada não restringe o emprego da $\mathrm{EaD}$ aos mestrados profissionais, mas é o que está acontecendo, uma vez que iniciativas desta natureza estão circunscritas a este nível de ensino.

Assim, surge a pergunta que norteou esta pesquisa: Em que estágio se encontra a regulamentação sobre o emprego da EaD na pós-graduação stricto sensu brasileira? Em função do exposto, este trabalho se justifica em virtude de sua importância para a comunidade científica, uma vez que aborda um tema ainda pouco discutido na academia.

O próximo tópico dedicar-se-á a apresentar o referencial teórico que sustenta esta pesquisa.

\section{Referencial teórico}

A EaD não é algo novo, pois sua história se estende por quase dois séculos, tempo esse que representa mudanças significativas na forma como a aprendizagem é viabilizada e a comunicação é estabelecida (Moore, Dickson-Deane \& Galyen, 2011), impulsionada em grande monta pelos avanços das tecnologias de informação e comunicação (TICs), o que faz com que muitas vezes a história da EaD se confunda com a das TICs. De envio de material didático por correio a transmissão radiofônica e, depois, televisiva, telefônica, e, mais recentemente, com o surgimento da Internet, novas possibilidades foram adicionadas a esta modalidade de ensino ao longo dos anos.

A variedade de mídias para viabilizar cursos a distância permite que haja uma multiplicidade de modelos disponíveis, como aulas transmitidas ao vivo por canais abertos, como é o caso do Telecurso da Fundação Roberto Marinho; modelos híbridos ou semipresenciais ou ainda blended learning, em inglês, que combinam a educação presencial com a EaD, modelo muito utilizado pelos cursos oferecidos pela UAB que pode ser definida como "um sistema integrado por universidades públicas que oferece cursos de nível superior para camadas da população que têm dificuldade de acesso à formação universitária, por meio do uso da metodologia da educação a distância (UAB, 2014)". 
Rubio (2007, p. 20) corrobora com UAB (2014) ao afirmar que a EaD "Se centra en ampliar el acceso a la educación, liberando a los estudiantes de las limitaciones de tiempo y espacio, y ofrece oportunidades flexibles de aprendizaje y formación". Aretio $(2012,38)$ por sua vez, define EaD como

a) La casi permanente separación del profesor/formador y alumno/participante en el espacio y en el tiempo, haciendo la salvedad de que en esta última variable, puede producirse también interacción síncrona.

b) El estudio independiente en el alumno controla tiempo, espacio, determinados ritmos de estudio $\mathrm{y}$, en algunos casos, itinerarios, actividades, tiempo de evaluaciones, etc. Rasgo que puede complementarse - aunque no como necesario - con las posibilidades de interacción en encuentros presenciales o electrónicos que brindan oportunidades para la socialización y aprendizaje colaborativo.

c) La comunicación mediada de doble vía entre profesor/formador y estudiante $\mathrm{y}$, en algunos casos, de éstos entre sí a través de diferentes recursos.

d) El soporte de una organización/institución que planifica, diseña, produce materiales (por sí misma o por cargo) y realiza el seguimiento y motivación del proceso de aprendizaje a través de la tutoría.

A definição de Aretio (2012), mostra que os avanços tecnológicos impactaram na própria definição do que é EaD, uma vez que, por exemplo, muitos autores sustentavam suas definições na separação física e temporal entre os sujeitos do processo educativo, mas as TICs mostraram ser possível estar próximo, mesmo estando geograficamente distante, mediante o emprego de ferramentas como chat, webconferência, entre outros.

O papel dos envolvidos no processo ensino-aprendizagem também foi ressignificado, uma vez que o professor deixa de ser o detentor do conhecimento para ser o facilitador/mediador e o aluno sai de uma posição passiva em que ele é o expectador e passa ser o ator principal do processo de construção do conhecimento, desenvolvendo a autonomia e a responsabilidade, ou seja, o aluno torna-se o centro do processo pedagógico (Costa, 2014).

Além disso, diferentemente do que ocorre em cursos presenciais nos quais há apenas a figura do professor e dos alunos em sala de aula, em cursos a distância, surgem, segundo Ferrari e Martins (2011), novos agentes como o:

- Revisor: responsável pela revisão ortográfica e gramatical dos textos, com o intuito de conferir ao material clareza, coerência e concisão, tornando a leitura interessante e fluída.

- Designer Instrucional: responsável pelo planejamento, seleção e desenvolvimento dos métodos e técnicas mais adequados ao público-alvo e suas necessidades de aprendizagem. Além disso, também se encarrega de selecionar materiais, atividades, objetos de aprendizagem em repositórios, entre outros, visando favorecer o processo de construção do conhecimento.

- Diagramador ou Designer Gráfico: responsável pela distribuição dos elementos gráficos no espaço de uma página, de acordo com as dimensões do material em que será impresso. Além disso, também define a palheta de cores e a hierarquização tipográfica, visando com isso apresentar as informações de forma clara e enfatizando o que é necessário. 
- Web Designer: responsável pela definição da identidade visual e funcional do material instrucional disponível na Internet, como banners, ícones, folders, entre outros, visando estruturar os conteúdos de modo que o aluno aprenda.

- Ilustrador: responsável pela criação de imagens, gráficos, personagens, entre outros que complementem um texto, provoque reflexões, chame a atenção dos alunos, tornando a leitura mais convidativa.

- Programador web: responsável por garantir que, independentemente do dispositivo utilizado para acessar o material do curso - computador de mesa, notebook, netbook, tablets e smartphones -, o aluno poderá usufruir da mesma forma de todo o material.

- Especialista audiovisual: responsável pelo acompanhamento, orientação, gravação e finalização de arquivos de vídeo e áudio, gravados pelo professor conteudista, que tenham como objetivo privilegiar provocações, proporcionar questionamentos e fomentar o desenvolvimento de um novo olhar para os fenômenos que se apresentam.

Além dos profissionais supramencionados pode haver outros envolvidos na produção de materiais didáticos, a composição da equipe variará de acordo com as características do projeto, mas todos os envolvidos somam esforços para contribuir com o ato de aprender, o que, segundo Mill, Oliveira e Ribeiro (2010) pode ser considerado como docência, nascendo daí o conceito polidocência que pode ser definido como

\begin{abstract}
equipe de educadores e assessores que - juntos, porém não na mesma proporção - mobilizam saberes de um professor: os conhecimentos específicos da disciplina; os saberes didático-pedagógico do exercício docente, tanto para organizar os conhecimentos da disciplina nos materiais didáticos quanto para acompanhar os estudantes; e os saberes técnicos, para manuseio dos artefatos e tecnologias processuais, para promover a aprendizagem de conhecimentos dos estudantes (Mill, Oliveira and Ribeiro, 2010, pp. 16-17).
\end{abstract}

Neste contexto, o papel do professor é ressignificado, passando a ser aquele responsável, entre outros, por:
a) estabelecer os fundamentos teóricos do projeto;
b) selecionar e preparar todo o conteúdo curricular articulado a procedimentos e atividades pedagógicas;
c) identificar os objetivos referentes a competências cognitivas, habilidades e atitudes;
d) definir bibliografia, videografia, iconografia, audiografia, tanto básicas quanto complementares;
e) elaborar o material didático para programas a distância;
f) realizar a gestão acadêmica do processo de ensino-aprendizagem, em particular motivar, orientar, acompanhar e avaliar os estudantes;
g) avaliar-se continuamente como profissional participante do coletivo de um projeto de ensino superior a distância (MEC, 2007, p. 20).

Como pode ser observado, o docente deixa de ser o único responsável por pensar, implementar e avaliar o que ocorre no contexto da sala de aula, passando a dividir essa responsabilidade com outros profissionais. Junta-se a este time a figura do tutor, cuja presença, segundo Costa (2007), é fundamental em cursos a distância ou semipresenciais. Ele é o responsável por "contribuir para o desenvolvimento dos processos de ensino e de aprendizagem e para o acompanhamento e avaliação do projeto pedagógico" (MEC, 2007, p. 21), "porém seu real papel ainda é motivo de 
grandes discussões, por existirem divergências em concepções e atuações correspondentes" (Mercado, Figueiredo \& Jobim, 2008, p. 97).

O tutor pode ser classificado como presencial que é aquele que "exerce sua função nos polos junto aos estudantes, em horários previamente estabelecidos, esclarecendo dúvidas em relação a conteúdos específicos e às tecnologias utilizadas nos cursos" (Costa, 2007, p. 11). Ou tutor a distância que atua fora do campus da IES, cuja "principal atribuição é o esclarecimento de dúvidas de conteúdo do material didático e ajuda de caráter geral ao estudante, através do telefone, de fóruns de discussão pela Internet, de participação em videoconferências, e outras tarefas, de acordo com a disponibilidade tecnológica e o projeto pedagógico (idem)".

Os profissionais supramencionados, além de outros, como coordenadores de curso, diretores de área e pró-reitores, somam esforços para colocar à disposição dos alunos um curso que atenda aos objetivos de aprendizagem.

Apresentado o referencial teórico que sustenta esta pesquisa, no próximo tópico o método escolhido será apresentado.

\section{Método de Pesquisa}

A pesquisa que se apresenta é qualitativa, pois tem como objetivo principal interpretar o fenômeno observado, quanto aos objetivos é exploratória, justificada, como coloca Gil (2008), quando a finalidade é proporcionar maior familiaridade com o problema, ideal no caso desta pesquisa em função da escassa produção científica na área. Para sua condução, optou-se pela pesquisa documental que muitas vezes é confundida com a pesquisa bibliográfica, mas enquanto a primeira consiste em identificar, verificar e analisar materiais que ainda não receberam tratamento analítico ou que podem ser reelaborados de acordo com os objetivos da pesquisa, a segunda se dedica a analisar materiais já elaborados, como livros e artigos científicos (idem).

Os documentos, segundo Rampazzo (2005), podem ser oriundos de arquivos públicos, oficiais ou jurídicos, como leis, portarias, registro de falência, entre outros ou de fontes particulares, como documentos de escolas, igrejas, partidos políticos, etc. No caso desta pesquisa, os documentos analisados são provenientes da legislação brasileira em vigor sobre EaD na pós-graduação stricto sensu e, também, da Coordenação de Aperfeiçoamento de Pessoal de Nível Superior (CAPES) que é uma fundação do MEC que desempenha um papel fundamental na expansão e consolidação da pós-graduação no país por meio de várias ações, entre elas o acompanhamento e avaliação dos cursos existentes neste nível de ensino.

Para analisar as evidências encontradas, optou-se pela utilização da técnica da análise documental que, segundo Caulley (1981), busca identificar informações que são importantes e relevantes para uma melhor compreensão do fenômeno, tendo como veículo orientador a questão de pesquisa.

Compreendida a opção metodológica, no próximo tópico os dados coletados serão apresentados e analisados à luz do referencial teórico utilizado nesta pesquisa.

\section{Analisando os dados}

A primeira etapa deste estudo é caracterizada pela organização do material coletado, quando tornou-se indispensável olhar para o conjunto de documentos de forma analítica, 
buscando verificar qual procedimento deveria ser adotado para torná-lo inteligível e atender ao propósito desta investigação.

Os documentos coletados foram organizados em pastas, separados por categoria. O critério utilizado para a organização foi a fonte dos materiais que, no caso desta pesquisa, eram oriundos de fontes públicas e oficiais como leis, portaria, resoluções, entre outros.

A leitura e o fichamento tiveram um papel central nesta fase, pois neste momento foram identificados trechos que faziam menção direta à $\mathrm{EaD}$ na pósgraduação stricto sensu ou que indiretamente trouxessem elementos que ajudassem a entender o emprego desta modalidade neste nível de ensino.

\subsection{O que diz a legislação}

Como resultado dos dados coletados foi possível identificar que o emprego da EaD na pós-graduação stricto sensu, assim como nos demais níveis de ensino, está previsto no Artigo 80 da Lei n. 9.394 (1996) que diz "O Poder Público incentivará o desenvolvimento e a veiculação de programas de ensino a distância, em todos os níveis e modalidades de ensino, e de educação continuada", cabendo aos órgãos responsáveis dos respectivos sistemas de ensino ou em parceria, conforme consta no Parágrafo $3^{\circ}$ do referido artigo, editar "As normas para produção, controle e avaliação de programas de educação a distância e a autorização para sua implementação (idem)".

A regulamentação do Artigo 80 da Lei n. 9.394 (1996) se dá por meio do Decreto n. 5.622 (2005), que em seu Artigo $2^{\circ}$, Inciso V, prevê o emprego da EaD em todos os níveis de ensino, desde a educação básica até o mestrado e doutorado. $\mathrm{O}$ referido decreto regulamenta, entre outros, em seu capítulo V, a oferta de cursos de especialização e menciona em seu Artigo 25 que "Os cursos e programas de mestrado e doutorado a distância estarão sujeitos às exigências de autorização, reconhecimento e renovação de reconhecimento previstas na legislação específica em vigor" (idem). Ainda segundo o artigo, o parágrafo $1^{\circ}$ traz que "Os atos de autorização, o reconhecimento e a renovação de reconhecimento citados no caput serão concedidos por prazo determinado conforme regulamentação" e no parágrafo $2^{\circ}$, com redação dada pelo Decreto no 6.303 (2007), que "Caberá à Coordenação de Aperfeiçoamento de Pessoal de Nível Superior - CAPES editar as normas complementares a este Decreto, no âmbito da pós-graduação stricto sensu".

A regulamentação pela Capes ainda não foi realizada e isso fica evidente ao observar os Documentos de Área - que traz as orientações necessárias para a proposição de novos cursos e gestão daqueles já implementados -, de todas as áreas do conhecimento (CAPES, 2014b), o que torna possível afirmar que não há nenhuma orientação específica para os interessados em ofertar cursos a distância ou semipresenciais, mesmo no caso de áreas que já possuem mestrados profissionais ofertados no formato semipresencial, criados em resposta a editais lançados pela própria Capes, visando formar uma rede nacional composta por IES públicas e pertencentes à UAB.

É válido ressaltar que o fato de escolher as IES pertencentes à UAB para compor uma rede nacional para oferta de programas de pós-graduação stricto sensu, já traz indícios importantes para compreender o que a Capes entende por modelo ideal para ofertar cursos a distância.

Como resultado dos editais lançados pela Capes, há no país seis mestrados profissionais oferecidos em rede e no formato semipresencial, são eles: Mestrado 
Profissional em Matemática em Rede Nacional (ProfMat), Mestrado Profissional em Letras (ProfLetras), Mestrado Nacional Profissional em Ensino de Física (ProFis), Mestrado Profissional em Artes (ProfArtes), Mestrado Profissional em Ensino de História em Rede Nacional (ProfHistória) e Mestrado Profissional em Administração Pública em Rede Nacional (ProfiAP).

O primeiro programa criado foi o ProfMat, mas todos os cursos têm como característica em comum a formação de professores que atuam na educação básica, exceção feita apenas no caso do ProfiAp que tem por objetivo "formar profissionais com nítido entendimento do papel do Estado no Brasil, do exercício da cidadania e preocupado com as questões éticas, sociais e ambientais que subsidiarão as políticas públicas que impactam a sociedade (CAPES, 2014)".

O único documento oficial localizado que não se restringiu a mencionar a possibilidade do emprego da $\mathrm{EaD}$ na pós-graduação stricto sensu, mas que trouxe algumas orientações neste sentido foi a Resolução CNE/CES n. 1 (2001) que estabelece normas para o funcionamento de cursos de pós-graduação, lato e stricto sensu, incluindo os ofertados a distância. O Artigo $3^{\circ}$ deste Decreto dedica-se a esta matéria e traz em sua redação que "Os cursos de pós-graduação stricto sensu a distância serão oferecidos exclusivamente por instituições credenciadas para tal fim pela União, [...] obedecendo às mesmas exigências de autorização, reconhecimento e renovação de reconhecimento estabelecidas por esta resolução".

E continua nos parágrafos que compõem o referido artigo. No parágrafo $1^{\circ}$ está previsto que os cursos de pós-graduação stricto sensu oferecidos a distância devem, obrigatoriamente, incluir provas presenciais. A mesma exigência de presencialidade, de acordo com o parágrafo $2^{\circ}$, se dá em relação à defesa da dissertação ou tese. O parágrafo $4^{\circ}$ dispõe que "A avaliação pela CAPES dos cursos de pós-graduação stricto sensu a distância utilizará critérios que garantam o cumprimento do preceito de equivalência entre a qualidade da formação assegurada por esses cursos e a dos presenciais (idem)”.

Lança-se luz para o parágrafo $4^{\circ}$, no momento em que diz que é preciso cumprir o preceito de equivalência de qualidade da formação assegurada tanto no formato presencial quanto no a distância. Mas como fazê-lo se não há orientações específicas nesse sentido, não a ponto de dar tratamento diferenciado a uma modalidade em detrimento da outra, mas para que as especificidades sejam consideradas neste processo.

Alguns questionamentos surgem como: Os programas devem contar com a presença de um tutor, tal como acontece nos cursos superiores de graduação e pósgraduação lato sensu? Se sim, qual o perfil desse profissional? Se não, quem acompanhará os alunos, principalmente nos momentos a distância? No que se refere ao material didático, que tipo de material será disponibilizado aos alunos? O programa contará com o apoio de uma equipe multidisciplinar para a produção dos conteúdos? Qual a carga horária máxima que poderá ser ofertada a distância? Questões como essas e outras precisam ser esclarecidas em um documento e disponibilizado para todos os pertencentes ao Sistema Nacional de Pós-Graduação.

As IES, públicas ou privadas, não pertencentes à UAB, mas que estejam interessadas em utilizar a EaD para ofertar cursos a distância ou semipresenciais, por não terem nenhuma orientação neste sentido, podem apresentar propostas, mas sem saber se estão no caminho certo ou não. Este foi o caso da Universidade Federal de Juiz de Fora, pertencente à UAB, mas que criou e aprovou o mestrado profissional em Gestão e 
Avaliação da Educação Pública não em atendimento a edital lançado pela Capes, mas em resposta ao amadurecimento das pesquisas nessa área. $\mathrm{O}$ mestrado funciona no formato semipresencial, voltado para a formação de diretores de escolas públicas e a técnicos dos órgãos de gestão da educação básica pública. Vale salientar que hoje, diferentemente do que ocorre com os cursos de graduação e pós-graduação lato sensu, não há um mecanismo que permita a consulta de quais instituições de ensino fazem uso da EaD no país.

Outro ponto que merece destaque é que os mestrados profissionais ofertados no formato semipresencial estão sendo utilizados em ações pontuais para, em grande parte, formação dos professores que atuam na educação básica. Esse formato atende ao disposto no Artigo 62 da Lei 9.394 (1996), parágrafo $2^{\circ}$, trecho incorporado pela Lei n. 12.056 (2009), que prevê que "A formação continuada e a capacitação dos profissionais de magistério poderão utilizar recursos e tecnologias de educação a distância". Indo na mesma direção, no parágrafo $3^{\circ}$, inciso III, do Artigo 87, estão previstos "programas de capacitação para todos os professores em exercício, utilizando também, para isto, os recursos da educação a distância" (Lei n. 9.394, 1996), cabendo ao Distrito Federal, Estados e Municípios, e, supletivamente, a União, desenvolver iniciativas desta natureza.

Aqui cabe uma reflexão, pois é sabido da necessidade de investir na qualificação do corpo docente que atua na educação básica, visando com isso melhorar a educação do país, mas, conforme disposto no último PNPG (2010), é preciso considerar também que há outras frentes que precisam ser atendidas como a agricultura, oceanografia, programas espaciais, política nuclear, saúde pública, desafios urbanos, problemas ligados ao clima, à energia e ao pré-sal, entre outros, será que a EaD não poderia ser um caminho para auxiliar iniciativas desta natureza, permitindo a criação de programas, acadêmicos ou profissionais?

Apesar de já haver no Brasil mestrados profissionais ofertados no formato semipresencial, na Portaria Normativa n. 17 (2009) que dispõe sobre os mestrados profissionais, não há nenhuma menção sobre o emprego da EaD neste nível de ensino, mesmo num momento em que todos os cursos oferecidos no formato semipresencial sejam mestrados profissionais. Também não há nenhuma menção sobre $\mathrm{EaD}$ na Portaria No. 193 (2011) que fixa as normas e procedimentos para a apresentação e avaliação de propostas de cursos novos de mestrado e doutorado.

Em suma, o sistema UAB tem contribuído para a consolidação da EaD no ensino superior brasileiro, mas ainda há um longo caminho até que esta modalidade de ensino seja institucionalizada no cenário da pós-graduação stricto sensu, principalmente em razão do preconceito ainda existente. A regulamentação pela CAPES é um caminho importante, pois seria uma forma de reconhecer que a $\mathrm{EaD}$ pode ser utilizada não apenas em situações pontuais, como é o caso da formação dos professores que atuam na educação básica, mas em outras situações cujo objetivo seja levar educação aos lugares mais recônditos deste país. É claro, sem deixar de lado o investimento necessário em infraestrutura física, tecnológica e de recursos humanos nas IES e em seus respectivos polos.

\section{Considerações Finais}

A necessidade de ampliar o número de mestres e doutores no país é evidente, sendo inclusive pauta de duas das 20 metas do Plano Nacional de Educação que vigorará entre 2011 e 2020. 
O alcance desse objetivo está condicionado, entre outras iniciativas, no emprego da EaD para ofertar cursos no formato semipresencial e em rede nacional, por instituições pertencentes à UAB. É válido ressaltar que, como foi colocado, iniciativas desta natureza ainda estão circunscritas aos mestrados profissionais.

Em função do exposto, a CAPES vive o desafio de equilibrar acesso com qualidade e é por isso que cursos a distância ou semipresenciais são vistos com preocupação, pois ainda há aqueles que acreditam que a oferta de cursos utilizando-se dos recursos da $\mathrm{EaD}$ pode fazer com que haja um retrocesso na qualidade alcançada e que fazem com que os cursos de pós-graduação stricto sensu sejam respeitados

Em suma, a UAB tem representado um papel importante na ampliação do acesso aos programas de pós-graduação stricto sensu, por meio da oferta dos mestrados profissionais em rede nacional e no formato semipresencial, mas ainda há um longo caminho a seguir para que a EaD seja legitimada neste nível de ensino.

\section{Referências}

Aretio, L. G. (2012). Estudios de educación a distancia. ¿Por qué va ganando la educación a distancia? Barcelona, España: Editora Ariel Educación.

Caulley, D. N. (1981). Document Analysis in Program Evaluation. Portland: Northwest Regional Educational Laboratory.

Coordenação de Aperfeiçoamento de Pessoal de Nível Superior (2011). Portaria Nº 193 de 4 de outubro de 2011. Disponível em: http://www.capes.gov.br/images/stories/download/legislacao/PORTARIA-N-193DE-4-DE-OUTUBRO-DE-2011.pdf. Acesso em: 23/6/2014.

(2014a). Programa de Mestrado Profissional em Administração Pública (ProfiAP). Disponível em: http://www.capes.gov.br/educacao-a-distancia/profiap. Acesso em: 23/6/2014.

(2014b). Documentos de Área. Disponível em: http://www.avaliacaotrienal2013.capes.gov.br/documento-de-area-e-comissao. Acesso em: 23/6/2014.

Costa, J. da C. (2007). Modelos de educação superior a distância e implementação da Universidade Aberta do Brasil. In Revista Brasileira de Informática na Educação. v. 15, n. 2. Disponível em: http://www.br-ie.org/pub/index.php/rbie/article/view/63/53. Acesso em: 23/6/2014.

Decreto n. 5.622, de 19 de dezembro de 2005 (2005). Disponível em: http://portal.mec.gov.br/seed/arquivos/pdf/dec 5622.pdf. Acesso em: 23/6/2014.

Decreto n. 5.800, de 8 de junho de 2006 (2006). Disponível em: http://www.planalto.gov.br/ccivil 03/ ato2004-2006/2006/decreto/d5800.htm. Acesso em: 23/6/2014,

Decreto n. 6.303, de 12 de dezembro de 2007 (2007). Disponível em: http://www.planalto.gov.br/ccivil 03/_Ato2007-2010/2007/decreto/D6303.htm. Acesso em: 23/6/2014.

Ferrari, F. B., Martins, R. X. (2011). Processos de Produção de Material Didático para Cursos a Distância e Matriz de Design Instrucional. In ESUD 2011 - VIII Congresso Brasileiro de 
Ensino Superior a Distância. Disponível em: http://www.cead.ufla.br/portal/wpcontent/uploads/2011/05/Artigo EaD 1 vers o final.pdf. Acesso em:23/6/2014.

Filatro, A. (2008). Design instrucional na prática. São Paulo: Pearson Education do Brasil.

Gil, A. C. (2008). Como elaborar projetos de pesquisa. 4. ed. São Paulo: Atlas.

Lei n. 9.394, de 20 de dezembro de 1996 (1996). Disponível em: http://portal.mec.gov.br/arquivos/pdf/ldb.pdf. Acesso em: 23/6/2014.

Lei n. 12.056, de 13 de outubro de 2009 (2009). Disponível em: http://www.planalto.gov.br/ccivil 03/ Ato2007-2010/2009/Lei/L12056.htm. Acesso em: $23 / 6 / 2014$.

Litto, F. M. (2012). Infrações que prejudicam a imagem da EaD. In Litto, F. M. \& Formiga, M. (orgs.). Educação a distância: o estado da arte 2 ed. São Paulo: Pearson Education do Brasil.

Mercado, L. P. L., Figueiredo, L. K. de A. and Jobim, D. R. de B (2008). Formação de tutores do curso piloto de administração a distância da Universidade Aberta do Brasil. In: Mercado, L. P. L (org). Práticas de formação de professores na educação a distância. Maceió: EDUFAL.

Mill, D., Ribeiro, L. R. de C., Oliveira, M. R. G. de (2010). Múltiplos enfoques sobre a polidocência na Educação a Distância Virtual. In (orgs.) Polidocência na Educação a Distância: múltiplos enfoques. São Paulo: EdUSFCar.

Ministério da Educação (2007). Referenciais de Qualidade para Educação Superior a Distância. Disponível em: http://portal.mec.gov.br/seed/arquivos/pdf/legislacao/refead1.pdf. Acesso em: 23/6/2014.

Moore, J. L., Dickson-Deane, C. and Galyen, K (2011). E-Learning, online learning, and distance learning environments: Are they the same? In Internet and Higher Education, n. 14, p. 129-135.

Portaria Normativa $N^{o} .17$ de 28 de dezembro de 2009 (2009). Disponível em: http://www.capes.gov.br/images/stories/download/legislacao/PortariaNormativa 17 MP.pdf. Acesso em: 23/6/2014.

Projeto de Lei $n$. 8035, de 2010 (2010). Disponível em: http://portal.mec.gov.br/index.php?option $=\mathrm{com}$ docman\&task $=\mathrm{doc}$ download\&gid $=$ 7244\&Itemid $=$. Acesso em: 23/6/2014.

Rampazzo, L. (2005). Metodologia científica: para alunos dos cursos de graduação e pós-graduação. São Paulo: Loyola.

Resolução CNE/CES n. 1, de 3 de abril de 2001 (2001). Disponível em: http://portal.mec.gov.br/seed/arquivos/pdf/tvescola/leis/CES0101.pdf. Acesso em: 23/6/2014.

Rubio, M. J. G. (2007). Orientación y metodología para la educación a distancia. Ecuador: Editorial de la Universidad Técnica Particular de Loja.

Universidade Aberta do Brasil (2014). $O$ que é. Disponível em: http://www.uab.capes.gov.br/index.php?option $=$ com content\&view $=$ article\&id $=6 \& \mathrm{I}$ temid=18. Acesso em: 23/6/2014. 